\title{
HIV/AIDS in South Africa: \\ Graphic signs countering the stigma and silence*
}

\author{
Nadine Chariatte (Cape Town)
}

\begin{abstract}
South Africa is one of the countries most affected by HIV/AIDS. Despite this strong presence of HIV/AIDS in South African society the disease remains stigmatised and is not openly talked about. The silence about HIV/AIDS maintained in everyday conversations and the superstitions associated with it have led to creative uses of social media to discuss HIV/AIDSrelated issues. This study aims to investigate how South African users resort to specific graphic signs to talk about HIV/AIDS online. The analysis is situated within a theoretical framework of small stories. An important feature of the small stories analysed is the stigmatisation of HIV/AIDS and numerous related issues. For this study 368 Facebook status updates and comments concerning HIV/AIDS and its side effects were analysed. All of the participants (80 in total), aged 14-48, lived in the Cape Flats area of Cape Town at the moment of data collection. In most cases the graphic signs display a graphic depiction of the physical, mental and social effects of the illness, different ways of transmission, and everyday life with HIV/AIDS. These semiotic practices employed on Facebook provide insight into how Capetonian users, on the one hand, express solidarity and sympathy with people suffering from HIV/AIDS. On the other hand, the graphic signs are used to (negatively) label and blame people affected by HIV/AIDS. This leads to acts of othering and distancing of people affected by HIV/AIDS. Thus, in the South African context social media have become an important space and means for communicating HIV/AIDS issues. As users from the Cape Flats draw on a range of graphic signs to discuss diverse HIV/AIDS-related issues online despite the stigmatisation, these graphic signs might create new opportunities to fight HIV/AIDS.
\end{abstract}

\section{$1 \quad$ Introduction}

This paper deals with a creative way of communicating about HIV/AIDS in South Africa on social media. HIV/AIDS is a prominent health concern in South Africa. One in eight South Africans is HIV-positive. Yet, HIV/AIDS is considerably stigmatised and silenced in South Africa (cf. Ashfort 2001; Delius/Glaser 2005; Masquillier et al. 2015; Maughan-Brown 2010). However, studies on HIV/AIDS in South Africa with a language focus are scarce (cf. Anthon-

\footnotetext{
* I would like to thank the editors of the special issue, Miriam A. Locher and Franziska Thurnherr, the anonymous reviewers and Clara M. Schmid, Clive Langdon and Emine Hasnaj for their helpful feedback. In addition, I am indebted to Blessing, Chanelle, Justin, Sibonile, Taariq Tammy-Lee and Ziyanda for their help with depicting the meanings of the graphic signs and their constituents.
}

Linguistik online 87, 8/17 - http://dx.doi.org/10.13092/lo.87.4176

CC by 3.0 
issen/Meyer 2008; Oostendorp/Bylund 2012; Saal 2012; Selikow 2004). The use of graphic signs to counter the HIV/AIDS stigma and silence has not yet been analysed in linguistics. In the context of this study, graphic signs are defined as schematic pictures consisting of ASCII characters, similar to emoticons. For their analysis the study draws on social semiotics, which attempts to understand and explain how the signs are used to "produce and communicate meanings in specific social settings be they 'micro' settings such as the family or settings in which the sign making is well institutionalized and hemmed in by habits, conventions and rules" (Kress/Van Leeuwen 1996: 264). The meanings of graphic signs reflect reality as imagined and influenced by the sign-makers' beliefs, values and biases. That is, the graphic signs studied can only be understood in their social setting of the Cape Flats in Cape Town, where the study is set. The Cape Flats, also commonly called "apartheid's dumping ground", are overcrowded, poverty-stricken, gang-infested townships, which are home to the majority of Cape Town's Coloured and Black population. In the Cape Flats, Internet usage is fairly widespread, even though it is mainly mobile-centric and mostly text-based content that is shared in combination with low-resolution images. Since part of the users are semi-literate, short texts, and pictorial and visual communication is preferred.

The aim of the present paper is to demonstrate how South African users resort to graphic signs in online conversations about HIV/AIDS to transcend the stigma and silence attached to being infected with the virus. Furthermore, the paper explores to what extent this is a gendered practice. The study is based on a data set collected on Facebook ${ }^{1}$ from users who live in the Cape Flats. The HIV/AIDS-related graphic signs occurring in the data were thematically analysed in context according to which aspects of HIV/AIDS they cover and categorised in terms of their social function. Thus, the research questions addressed in this paper are: 1. Which HIV/AIDS-related words or expressions do the graphic signs substitute and how can they be thematically categorised? 2. How are the graphic signs used in the context of the Facebook posts to position the social relations of people affected by HIV/AIDS? ${ }^{2}$ This paper is structured as following: in section 2 the scene is set (2.1 HIV/AIDS in South Africa, 2.2 small stories and performances), in section 3 the methodology is presented, and in section 4 the results are discussed. Finally, in section 5, the key points of this paper are summarised and ways of applying the findings are suggested.

\section{Context}

\subsection{HIV/AIDS in South Africa}

South Africa is one of the countries most affected by HIV/AIDS: According to 2015 UNAIDS data 7 million South Africans live with HIV/AIDS, which means a $19.2 \%$ prevalence rate among adults (15-49 years old). In addition, 180,000 people died in 2015 due to AIDS and 380,000 got newly infected. These figures are especially salient as South Africa has the largest antiretroviral therapy program worldwide with 3.4 million people receiving antiretro-

\footnotetext{
${ }^{1}$ Facebook is a very popular social media platform in the Cape Flats as it can be used for text-based communication (and low-resolution images). In comparison to other social media offers this makes it an affordable channel of communication, which allows users to communicate to multiple members of their social network at once.

2 "People affected by HIV/AIDS" refers to those people that are HIV-positive, but also to their relatives and friends, in short, all people whose lives are somehow affected by the HIV/AIDS epidemic.
}

ISSN 1615-3014 
viral treatment in 2016. HIV/AIDS prevalence among South African women is nearly twice as high as among men. The infection rate among young women, aged 15-24, is more than four times greater than that of their male peers (Shisana et al. 2014: xxviii). The disparity in HIV/AIDS prevalence between genders can be attributed to women being more affected by poverty, the lower status of women and gender-based violence, the latter accounting for more than $20 \%$ of new infections in young women (Van Damme/Kober/Kegels 2008: 2019). The HIV/AIDS epidemic is not only disproportionally distributed by age and gender, but also by population group, socioeconomic status, and locality type. The radically uneven distribution of HIV/AIDS is mainly due to the structural inequalities shaped by colonialism and apartheid (Farmer 2003). Black and Coloured South Africans have a manifold higher likelihood to be HIV-positive than their White counterparts. There is an inverse relationship between socioeconomic status and HIV status, with those from the lowest income bracket being seven times more likely to be HIV-positive than those with the highest income. Living in an urban informal settlement constitutes a very high HIV-risk in South Africa (Shisana et al. 2014: 47-51).

Despite the strong presence of HIV/AIDS in South African society, the disease remains relatively stigmatised and silenced. Stigma is a social construction of deviation from an ideal or expectation that contributes to a powerful discrediting social label, which reduces the way individuals see themselves and others view them (Parker/Aggleton 2003: 13). Parker/Aggleton (2003: 14) add that stigma is not a "static attitude" but "a constantly changing (and often resisted) social process". Goffman (1963: 3) describes stigma as a "process of devaluation" of an individual and the exclusion from full societal acceptance, in which certain attributes are defined by others as discreditable or unworthy, resulting in the person stigmatised becoming "discounted" or "tainted". According to Goffman (1963: 3) there are three aspects of stigma: physical deformities or impairments, blemishes of individual character, stained social identities. All three aspects affect people suffering from HIV/AIDS. Previous studies (Bond et al. 2002; Liamputtong 2013; Steward et al. 2008; Thomas 2006) have identified three broad types of HIV/AIDS-related stigma: 1) self stigma, manifested in self blame and self-deprecation of people living with HIV/AIDS; 2) perceived stigma, the fear people with HIV/AIDS have of being stigmatised if they disclose their HIV-positive status; 3) enacted stigma, when people are actually discriminated against due to their (actual or perceived) HIV status. Common sources of HIV/AIDS stigma are often poverty, low education, and sociocultural beliefs within the local context (cf. Herek et al. 2003; Ogden/Nyblade 2005; Shisana/Simbayi 2002; Stadler 2003; Volks 2004): Christian and Muslim faith condemning "transgressive" sexuality (promiscuity) and believers in spirits and witchcraft seeing HIV/AIDS as a curse. Stigma may involve actions such as gossip, verbal and physical abuse, and distancing from the person with HIV/AIDS. It can range from subtle actions to extreme degradation, rejection and abandonment. HIV/AIDS stigma leads to silence deterring people from testing, disclosing, seeking treatment, talking about sexual relationships, and exchanging experiences. Ogden/Nyblade (2005) regard stigma as a key driver of the HIV/AIDS epidemic, especially in Southern Africa. Usually disease-stigma historically decreases as the illness is better understood and treatment is widely available. However, this appears not to be the case with regard to HIV/AIDS in South Africa (cf. Herek 2002; Maughan-Brown 2010).

Stigma often involves verbal taboo, that is, the avoidance of mentioning the stigmatised. HIV/AIDS is shamed and silenced by virtue of its connections with disease, death and sex. 
In South Africa women are more affected by HIV/AIDS stigma and the resulting silence than men (Duffy 2005: 16). Silence can refer to a collective social phenomenon, which is a result of prohibition and policing (Foucault 1978: 27). In other words, it is supressed discourse and is, thus, an effect of power. Dominant discourses marginalise or silence certain vocabularies and values while permitting and legitimatising others. Silence can also refer to a more personal dimension. According to Morrell (2003: 44), "[a] person who either feels unable to talk about certain subjects or emotions or is unaware of certain aspects of his or her history suffers from silence". The collective and the personal aspects of silence cannot be separated and fuel each other. Common ways of silencing HIV/AIDS in South Africa are either by avoiding to talk about it at all or by using other terms, such as: isidliso (a form of poisoning inflicted by witches), ulwazi ('that thing'), red death, black poison, retroviral virus, (to) be very sick, (to) have sore blood (cf. Ashforth 2001; Black 2013; Campbell et al. 2007). According to Ashforth (2001: 12), "[t]o talk of a 'stigma' attached to AIDS in contemporary South Africa without understanding the witcheraft ${ }^{[3]}$ dimensions is [...] to risk misunderstanding both the nature of community power relations and the impact of the epidemic". The silence about HIV/AIDS maintained in everyday conversations and the beliefs associated with this illness have led to creative ways to discuss HIV/AIDS-related issues on social media. That is, an alternative code consisting of graphic signs has emerged to break the silence and to circumvent HIV/AIDS-related taboo words and expressions.

\subsection{Small stories and performances}

The study is situated within a theoretical framework of "small stories" (cf. Bamberg/Georgakopoulou 2008; De Fina 2008; De Fina/Schiffrin/Bamberg 2006; Georgakopoulou 2007), that is, those moments when people recount something, however small or seemingly trivial. The focus lies on the functions and social actions that small stories perform in people's everyday lives. People use small stories to "create (and perpetuate) a sense of who they are" both in the interactional moment as well as in relation to the dominant discourses which constitute their context (Bamberg/Georgakopoulou 2008: 379). This "sense of who they are" is co-constructed by the interlocutors, which often results in a "discursive production of a diversity of selves" (Davies/Harré 1990: 47) - in positioning. Positioning is "the discursive process whereby selves are located in conversations as observably and subjectively coherent participants in jointly produced story lines" (ibd.: 48). In other words, positioning is an interactional phenomenon producing interpersonal relations. Thus, positioning is a dynamic process in which the speakers "actively and agentively select, resist and revisit positions" resulting in a relational and performative view of self and other (Georgakopoulou 2007: 123). However, the participants in an interaction not only position themselves and their interlocutors, but also "other", absent third parties. An interesting case of positioning work can be observed in South Africa, more specifically in Cape Town. Facebook users from the Cape Flats tell omnifarious HIV/AIDS-related small stories with graphic signs to transcend the stigma and silence. In their Facebook interactions users position the self and the other in the sphere

\footnotetext{
${ }^{3}$ Ashfort (2001: 5) explains the witchcraft issue as follows: "Cases of premature death or untimely illness in Africa are almost always attributed to the action of invisible forces, frequently those described as 'witchcraft'. Witchcraft in the South African context typically means the manipulation by malicious individuals of powers inherent in persons, spiritual entities, and substances to cause harm to others".
}

ISSN 1615-3014 
of HIV/AIDS stigma and silence by means of these graphic signs. The sum of these small stories containing HIV/AIDS-related graphic signs presents us with a "big story" of HIV/AIDS stigmatisation and silencing in the Cape Flats.

Graphic signs are artful and carefully crafted, and play a crucial role in the users' HIV/AIDS discourse. They are non-routine modes of speaking and demand "special attention and heightened awareness to the act of expression" (Bauman 1977: 11). Hence, they are performances, or to use Deumert's (2014, forthcoming) terminology "small performances". Deumert (forthcoming: 18) uses the term "small performances" in analogy to small stories. Both of them are fleeting, momentary, non-routine, short displays of linguistic skills embedded in everyday social practices. According to Bauman (2000: 4), "performance is a consequential, efficacious mode of linguistic practice, a potent means of creating, negotiating, and displaying social meaning and value in the communicative accomplishment of social life". Performance is an act of stance-taking (Jaffe 2009). The performer seizes a particular position within their act of expression by invoking the performance frame in an ongoing interaction (Bauman 2011: 700). That is, the users from the Cape Flats with their small performances challenge the stigma and silence - saying the unsayable through graphic signs. These small performances can subvert the dominant narrative of issues that are taboo, that which cannot be named or spoken. They give voice to the silenced, present alternative stories, raise awareness and press for activism and social change. The choice of social media as a setting for small performances is certainly no coincidence. Apart from offering the cheap, text-based affordances, social media constitute a space that is seemingly more anonymous and beyond the social control of the Cape Flats residents, and gives the opportunity to reach a larger audience.

\section{$3 \quad$ Data and methodology}

For this study 368 Facebook status updates and comments concerning HIV/AIDS were analysed. ${ }^{4}$ None of the data comes from private messages. All of these Facebook posts contained some sort of graphic signs to talk about HIV/AIDS. Even though HIV/AIDS is stigmatised and silenced in South Africa, this does not mean that it is not talked about at all. In this paper, however, the focus is on the use of graphic signs in Facebook posts that allow a hedged way of addressing the topic.

A friends-of-friends/snowball approach was used for data collection as the profiles are private. This means that many of the participants know each other offline. The main language of the posts was English, mixed with Afrikaans and/or isiXhosa. The participants in this study (80 in total), aged 14-48, lived at the moment of data collection in Cape Town, in the Cape Flats.

Due to HIV/AIDS being a sensitive topic in South Africa, detailed ethical considerations were taken into account. No data was collected without the participants' prior informed consent, which was obtained via private message. In case of the participants who deceased during the study period, their relatives' consent for the use of data already collected was obtained. Since a considerable part of the South African population believes to a varying degree in spirits, the

\footnotetext{
${ }^{4}$ The 368 Facebook posts are part of a larger (roughly 1 million words) corpus of Facebook conversations of more than 200 Cape Flats residents. This corpus was searched for graphic signs in general and consequently those related to HIV/AIDS were selected for this study.
}

ISSN 1615-3014 
spirits' consent was gained through a sangoma ('traditional healer/diviner'). Obtaining the spirits' consent was undertaken to make those participants for whom this was relevant more comfortable. Furthermore, pseudonyms were used for people's names, place names, gang names, names of institutions, etc. Once the data was pseudonymised the participants had the opportunity to check if any more information needed to be changed and take their final decision whether the data collected from them could proceed to analysis.

The data collected was qualitatively analysed with the TAMS Analyzer software. In a first step, the data was sorted according to the different graphic signs employed. Next, the meanings of the graphic signs were established with the help of local participants. The collection of graphic signs was then checked for variation. Finally, the graphic signs were sorted thematically to study their positioning function in terms of social relations. For this last step it was examined how the graphic signs were used in the initial post and the comments to this post. In other words, the graphic signs were explored in the context of an evolving interaction on Facebook. The analysis of the graphic signs is as much social as linguistic as HIV/AIDS presents such a massive social challenge in South Africa, particularly in underprivileged areas, such as the Cape Flats.

\section{$4 \quad$ Results}

Users from the Cape Flats resort to a variety of specific graphic signs to talk about the often stigmatised and silenced topic of HIV/AIDS in their digital discourses. These graphic signs depict the physical, mental and social effects of the illness, different ways of transmission, and everyday life with HIV/AIDS. Moreover, it is a semiotic practice to express solidarity and sympathy with people affected by HIV/AIDS. On the other hand, people affected by HIV/AIDS are in some cases negatively labelled and blamed through the use of these graphic signs. Hence, the negatively charged uses of graphic signs may function as acts of distancing from those affected and othering them. In section 4.1, I present the different meanings of the graphic signs. They can be divided into those presentating the physical, mental and social effects of HIV/AIDS (4.1.1), those offering accounts on the ways of transmission of HIV (4.1.2), and those presenting accounts on everyday life with HIV/AIDS (4.1.3). These meanings are in many cases overlapping; however, this classification helps to understand for which aspects of HIV/AIDS Cape Flats residents use graphic signs. In section 4.2, I describe the social functions the graphic signs acquire in terms of interpersonal positioning in the Facebook interactions. On the basis of my thematic/functional analysis, the functions of the graphic signs are expressions of solidarity and sympathy (4.2.1) versus expressions of (negative) labelling and blaming (4.2.2); the latter can eventually lead to distancing and othering (4.2.3). Below, the different uses and functions of graphic signs in digital discourses on HIV/AIDS are analysed and illustrated with examples.

\subsection{Meanings of the graphic signs}

The first part of the results is dedicated to give an overview of which words or expression are substituted with graphic signs in Facebook posts about HIV/AIDS. The analysis is focused on the thematic categorisation of the graphic signs, which are used to circumvent the stigma of talking openly about HIV/AIDS. That is, I examine the graphic signs employed to substitute 
HIV/AIDS-related words or expressions deemed taboo by the users. The graphic signs replacing these taboo words and expressions can be classified into three main fields: 1) physical, mental and social effects of HIV/AIDS; 2) ways of transmission; 3) everyday life with HIV/AIDS. This exploration of the meanings of the graphic signs is the basis for the second part of analysis on their social functions.

\subsubsection{Physical, mental and social effects of HIV/AIDS}

HIV/AIDS has physical, mental and social effects on people suffering from the illness and their social environment. These effects go hand-in-hand with the three aspects of stigma identified by Goffman (1963), as seen in section 2.1. Next, I discuss an example of each of the three areas - a) physical, b) mental and c) social.

a) Physical effects

In the first example, a 43-year-old woman, pseudonymised as Fawzi, complains about her physical afflictions from HIV/AIDS. The Facebook posts are first presented in their original version in italics with the graphic signs highlighted in bold. This is followed by a transliteration/gloss in English where bold is used to paraphrase the graphic signs.

$$
\text { Fawzi (F, 43): }
$$

Eks al gatvol my $\boldsymbol{d} \boldsymbol{b} \neg$ ᄀ... $\ddot{\boldsymbol{U}}$ its baie soar

'I am already fed up my glands are swollen, (I suffer from) itchiness and mouth ulcers it is very sore'

Fawzi employs the graphic sign $d b$ as a figurative depiction of her swollen lymph nodes, i. e. displaying an enlarged gland protruding to the left and right side of her neck (which is represented by the space in between the letters and the vertical lines of $d$ and $b$ ). This graphic sign comes in combination with two others: $\neg \neg \ldots$ means 'itchiness' and represents a scratching hand, whereas $\ddot{U}$ stands for ulcers in the mouth.

b) Mental effects

In example (2), Roocher uses particular graphic signs to describe the mental effects HIV/AIDS has on her.

$$
\begin{array}{ll}
\text { Roocher }(\mathrm{F}, 21): & \text { it mkes me soo }\{0\} 8 O \backslash,\{O\} 8 O \backslash \text {, evry day } \\
\text { 'It makes me so depressed, anxious and down, depressed, anxi- } \\
\text { ous and down every day' }
\end{array}
$$

The mental effects mentioned by Roocher are those of feeling depressed $\{O\}$, anxious $8 O$ and down $\backslash$,. The graphic sign $\{O\}$ represents a head $O$ that is captured within mental boundaries $\{$ \}. Similarly, in $8 O$ a head $O$ is threatened by an undefined fear 8,8 either refers to eyes bulging in fear or to a turned around infinity symbol to make reference to an infinite number of fearful things. Finally, \, stands for an arrow pointing downwards. She emphasises the impact of her suffering by repeating the graphic signs and stressing that this happens to her every day. 
c) Social effects

Nkululeko talks about the negative social effects of being HIV-positive by means of graphic signs in example (3).

(3) Nkululeko $(\mathrm{M}, 36)$ :

eish I could cope if it werent for ]] I [I. and I was already $\mathbf{L}=>$ in Mqanduli nentloni

'Eish I could cope if it weren't for the social isolation. and I was already chased away in Mqanduli ashamed'

Nkululeko states that he was $L=>$ 'chased away' in his hometown Mqanduli and that now in Cape Town, where he currently lives, is exposed to ]] I [ [ 'social isolation'. He has difficulties coping with the loneliness resulting from his HIV status. In the first graphic sign a lonely person $I$ is shunned by those around him/her who turn their back on this person $]]$ [ [. The second graphic sign depicts a kicking leg through $L$ plus an indication that what was hit by the leg was kicked away $=>$.

These three examples show how HIV/AIDS negatively affects the well-being of patients. The patients are physically affected by swollen glands, mouth ulcers and itchiness (as in the case of Fawzi in example (1)), as well as, among others, flu-like symptoms, aches and pains, fatigue, cough, respiratory infections, kidney damage, skin sores, and shingles. Moreover, patients suffer mentally from depression, anxiety (as described by Roocher in example (2)), dementia, fear, stress, anger, sadness, feeling helpless and overwhelmed, among other symptoms. Finally, the impact of HIV/AIDS on the patients' social life is massive and ranges from social isolation, being shunned (reported in example (3) by Nkululeko) to discrimination, aggravated or denied access to services, employment and housing, and mobility restrictions. Those suffering from HIV/AIDS, like Fawzi, Roocher, and Nkululeko, are only too well aware of the fact, and in many cases have experienced themselves that the physical, mental and social effects of HIV/AIDS are highly related to stigmatisation. The effects of HIV/AIDS listed above are the most frequently expressed (through graphic signs) in the dataset analysed. Users tend to accurately list the different effects of HIV/AIDS they are experiencing and, hence, a wide array of graphic signs expressing these effects is in use. Due to the constant risk of stigmatisation, people affected by HIV/AIDS are often reluctant to openly talk about the impact this disease has on their bodies, minds and social lives. However, many patients feel the urge to remain silent about their suffering, but at the same time to somehow share their experiences with others. An ingenious means to discuss the effects of HIV/AIDS in a climate of stigma and silence predominating in the Cape Flats is the use of fairly conventionalised graphic signs, as for instance $d b, \neg \neg \ldots, \ddot{U},\{O\}, 8 O, \backslash,, L=>$ or $]] I[[$, in the sense that a considerable part of the local community of users would be used to them and understand them in the context of a post, and that there are recurring elements carrying a similar meaning, which can be combined to form diverse graphic signs. These graphic signs, thus, constitute a way for people suffering from HIV/AIDS to transcend the taboo surrounding this virus and feel relief by communicating.

\subsubsection{Ways of transmission}

A crucial aspect of HIV/AIDS that can be highly stigma-loaded is the way of transmission. In South Africa the main route of transmission is through sexual intercourse - consented or 
forced. Due to the stigma attached to having contracted HIV and its relation to sexual intercourse, which for many people is another taboo topic, revealing how one has been infected would rarely happen if not in a covert way, such as through graphic signs. Additionally, some South Africans believe that the spirits inflicted HIV upon somebody. Another frequent means of transmission is from mothers to their children, even though it was curbed over the past decade thanks to the massive rollout of antiretroviral therapy to pregnant women. The following Facebook posts exemplify how the use of graphic signs enables users suffering from HIV/AIDS to share their experiences of the ways in which HIV was transmitted to them.

In (4), Anele describes how she got infected by a male (ex-)partner. Meshirl reacts to Anele's small story by showing her support.

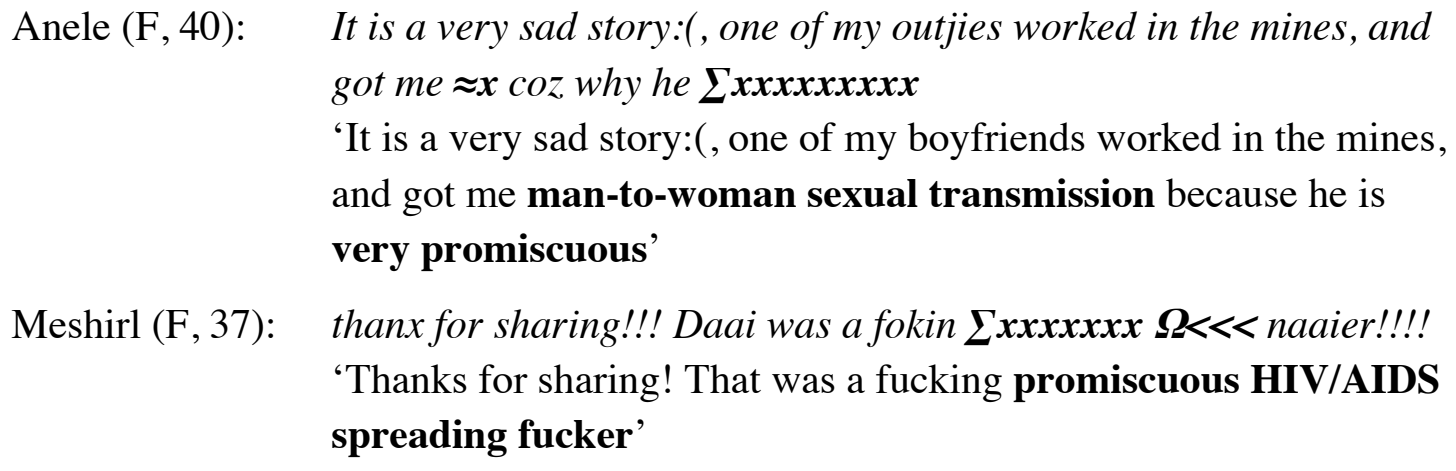

Anele uses $\approx x$ to express that she contracted HIV through man-to-woman sexual transmission. She explains the transmission by the promiscuity $\sum x x x x x x x x x$ of her boyfriend, who worked in the mining industry, which means that he spent weeks or even months in the mining areas without being able to visit her in Cape Town. Meshirl then thanks her for sharing her story, which by other means than through graphic signs is not very common. She shows Anele her support by condemning the boyfriend and labelling him as $\sum x x x x x x x$ 'promiscuous' and $\Omega<<<$ 'HIV/AIDS spreading'.

Two of the three graphic signs in example (4) contain the element $x$ which represents a woman. According to the information gathered from local people this meaning can be explained by the similarity of the $\mathrm{x}$-shape to the silhouette of a woman wearing a dress or by the $x$ standing for an $\mathrm{X}$ chromosome and, thus, portrays a woman. Hence, the graphic sign $\approx x$ depicts a woman who is getting HIV from male sperms represented by $\approx$. Likewise the multiple repetition "x" indicates a multitude of women in the graphic sign $\sum x x x x x x x x x$ who are all bound to the actions of a man. In other words, the graphic sign shows the sum (hence the $\Sigma$ ) of the sexual encounters of the male in question. Furthermore, the graphic sign $\Omega<<<$ consists of two elements: $\Omega$ (Omega, the final letter in the Greek alphabet) and $<<<$. The first symbolises HIV/AIDS as deadly, as the end. The latter stands for a massive spread: the angle bracket figuratively depicts spreading, which is reinforced by the triplication of the $<$.

Shanaaz contracted HIV when she was gang-raped as she explains in example (5). However, she does not receive a supportive comment on her disclosure, but a reproach from Taliep, who questions her behavioural integrity.

Shanaaz (F, 29):

my friend, $i$ was $Y Y \_Y Y$ en $\sim+$ now I ve to ce wat I do

'My friend, I was gang-raped and got infected with HIV now I

have to see what I do'

ISSN 1615-3014 
Taliep (M,34): $\quad$ what het jy gedoen? why did you ; $S_{j}$ to bring $\sim+$ to you?

'What have you done? Why did you anger the spirits to bring an HIV infection to you?'

Shanaaz addresses her post (status update) to my friend, even though from the context of the conversation it is not clear if this address refers to Taliep. She states that a violent sexual encounter, which she refers to as $Y Y_{-} Y Y$ 'gang-rape', has lead to her HIV infection. Shanaaz adds worryingly that she is uncertain about what to do in her situation. Instead of offering consolation, Taliep asks her what she has done. This is a means of reproaching her with bearing the blame for her HIV infection. He goes on to blame her of having angered the spirits iS;, who punished her with HIV. ${ }^{5}$

The graphic signs in (5) can be explained as following: Firstly, in $Y Y_{-} Y Y$ the _ depicts the rape victim who is pinned down/crushed. The victim is surrounded, even trapped, by the rapists who are represented by the $Y Y Y Y$. The shape of $Y$ resembles a man forcing himself on a woman and penetrating her, the upper lines of the $Y$ stand for the man's arms, with which he holds down the woman and the lower line is either his legs and/or his penis. The $Y$ could also be interpreted as the (male) Y chromosome. Secondly, in $\sim+$ the first part $\sim$ symbolises sperm, that is, a transmission of HIV, which is represented by the second part + . Thirdly, $i S_{i}$ consists of $S$ standing for 'spirits' since $S$ is the initial letter of spirits and/or since the shape of $S$ looks like a genie hovering in the air. Moreover, $i j$ indicate that the spirits are angered or irritated: the upside down exclamation marks stand for an amiss state of mind, in addition, the dot of the $;$ depicts bubbling up anger.

In example (6), Jamesello explains that he was born HIV-positive, as his mother transmitted the virus to him.

Jamesello (M, 15): Look I was born 0+ I don't kno nothin else not. ek is $n \boldsymbol{B}>\boldsymbol{O}$ case 'Look I was born HIV+ I don't know anything else. I am a mother-to-child transmission case'

Jamesello resorts to the graphic sign $0+$ to express that he was born HIV-positive (in other words, he is seropositive in terms of HIV, seropositive sounds/looks like zero positive, hence $0+)$. He adds that he does not know any other condition, as he has been HIV-positive his entire life. He concludes with positioning himself as a $B>O$ 'mother-to-child transmission' case. This graphic sign depicts a mother's breast with a $B$, the arrow $>$ symbolises the transmission of the virus, and $o$ stands for the baby or more specifically its mouth. However, it has to be noted that HIV transmission from mother to infant mostly occurs in utero.

The examples (4)-(6) illustrate how the graphic signs give people a possibility to communicate about their way of having gotten infected with HIV. The transmission of HIV/AIDS is one of the most gendered aspects of those dealt with in this paper. On the one hand, Jamesello is one of the only male participants to clearly state how HIV was transmitted to him. In the great majority of the other instances it is women telling their HIV transmission stories, which are nearly always related to sexual encounters with men. On the other hand, these different experiences make the use of graphic signs even more important for women, since they can

\footnotetext{
5 There are no further comments after Taliep's.
} 
more easily express that they were victims of sexual violence or of their partners' promiscuity, like Shanaaz and Anele. This also implies a more or less subtle blaming of men for the transmission of HIV to women through their sexual behaviour. It is interesting to note that men would certainly not accept any blame, but neither directly accuse women of sexually misbehaving. As does Taliep, men tend to impute women with committing general misconduct for which they are punished with HIV/AIDS (by the spirits). In sum, graphic signs are a means for people suffering from HIV/AIDS to tell others how they became HIV-positive, which as such often causes much shame, and even more so as it is intimately related to sex. Graphic signs also allow users to subtly hold others responsible for their status.

\subsubsection{Everyday life with HIV/AIDS}

HIV/AIDS affects the lives of people in the Cape Flats in manifold ways. It directly affects those infected, their families and friends. However, the high prevalence rate in the Cape Flats poses a threat to all residents and has an indirect effect on their daily lives. Despite being an everyday issue in many people's lives, it is not openly talked about how HIV/AIDS is part of their daily routines. Users prefer to resort to social media and graphic signs for this aspect as well, such as in examples (7)-(9).

In (7), Bradley and Goodwill discuss how antiretroviral medication constitutes an integral part of their everyday practices and how HIV/AIDS affects their sex life.

$$
\begin{aligned}
& \text { Bradley (M, 28): } \quad \text { Vandag was horrible ek het amper gechoke } 12^{\circ \circ} \text { oo and then the } \\
& n: \tilde{\boldsymbol{O}} \\
& \text { 'Today was horrible I almost choked } 12 \text { pills and then vomiting } \\
& \text { and not feeling well' } \\
& \text { Goodwill (M, 25): Yebo kubi morning big big } O O_{\text {O lunch many many }}^{\circ} \circ \circ \circ \circ \circ \\
& \text { dinner agen } \mathrm{O}^{\circ} \mathrm{O}^{\circ} \\
& \text { 'Yes it's terrible morning very big pills lunch very many pills } \\
& \text { and for dinner again pills' } \\
& \text { Bradley: } \quad \text { And I should use } \sim \supset \text { for } \boldsymbol{Y} \text { my ladies } \\
& \text { 'And I should use condoms for having sexual intercourse with } \\
& \text { my ladies' }
\end{aligned}
$$

Bradley starts with recounting his awful experience that day: how the 12 pills ${ }^{\circ} \circ o$ (the circles presenting different sizes of numerous pills) he had to take almost made him choke, he was vomiting $n$ : ( $n$ stands for an open mouth turned to the floor and : is the vomit falling off the mouth) and not feeling well $\tilde{O}$ ( $O$ symbolises a head and the tilde above means dizziness). Goodwill co-constructs the experience by emphasising that it is terrible, that his daily routine consists of taking $O O$ 'very big pills' in the morning, ${ }^{\circ} \circ \circ \circ \circ \circ \circ$ 'very many pills' at lunchtime, and $O^{\circ} O^{\circ}$ '(different) pills' again at dinnertime. The different graphic signs depicting pills do so by symbolising the round shape, the various sizes and the amount of the pills. 
However, their HIV-positive status ${ }^{6}$ does not only affect their everyday life in terms of their high intake of medication, but also their sex life. Bradley adds to their conversation that he should $\sim \supset$ 'use condoms' ( $\sim$ represents sperm that is blocked by $\supset$, whose shape resembles a condom) for $Y$ 'having sexual intercourse' (similar to example (5) $Y$ stands for heterosexual intercourse, even though in this case it is unclear whether it is consented) with his female partners. Goodwill responds that he feels too weak for sexual intercourse, that is, for him sex is no longer a daily routine.

HIV/AIDS has also a great impact on those cohabiting with an infected person, particularly in an informal housing situation, as described in example (8).

$$
\begin{aligned}
& \text { Inge (F, 43): } \quad \text { when is the goverment giving us a propa house? Treace have allday } \\
& \quad \text { u::: and sometime she also have n::: }
\end{aligned}
$$

'When is the government going to give us a proper house? Treace has all day diarrhoea and sometimes she also has vomiting'

Bjonn (M, 39): hoekoma don't you drop haar in the morning by the latrines and haal vi ha in the evening. then you stop the :::+ in your sheck 'Why don't you drop her in the morning at the latrines and pick her up in the evening. Then you stop the HIV/AIDS mess in your shack'

Inge: $\quad$ because $i$ don’t want hers to be $¥$ again and again she is ;I to weeak to go there

'Because I don't want her to be raped again and again she is too

skeletal and too weak to go there'

Inge opens the conversation between her and Bjonn with a rhetorical question about when the government will provide houses to her community. She is in dire need of formal housing because the lack of proper sanitation facilities in her informal housing structure is unbearable due to her daughter Treace, who is infected by HIV. Inge laments that Treace frequently suffers from $u::$ 'diarrhoea' and sometimes also from $n::$ 'vomiting'. This causes a sanitary strain on Inge and her other family members, given that they neither have running water nor proper sanitation facilities in their shack. Therefore, Bjonn suggests to drop Treace in the morning at the public toilets and pick her up in the evening in order to avoid the $::+$ 'HIV/AIDS mess' in her housing structure. Inge refutes the suggestion using two graphic signs as arguments: She does not want her daughter to be repeatedly $¥$ 'raped' and thinks that Treace is $; I I$ 'too skeletal' and too weak to spend her days at the public toilets.

The graphic signs used in (8) are partly already familiar from previous examples. For instance, $n:::$ is a variation of the graphic sign $n$ : in (7) with a multiplication of the second element : to indicate that it is in this case severe vomiting. In analogy with this graphic sign $u:::$ can be understood as depicting severe diarrhoea indicated by turning upside-down the first element $n$ into $u$. These two graphic signs lead to the comprehension of the next one: $: \cdots+$. Its first part $::$ symbolises the product of the vomiting and diarrhoea, and the second part + links the resulting mess to HIV. Another variation of a graphic sign encountered previously is $¥$.

\footnotetext{
6 This is background knowledge.
} 
The $Y$ depicts the rapist who in this case penetrates the rape victim represented by the two horizontal lines. The last graphic sign in this example $i I I$ consists of two elements, as well. The first part $;$ indicates that it is something disturbing or discomforting, in other words, it is amiss. The second part $I I$ is a reduplication of $I$, which depicts an extremely lanky body. The reduplication has the effect of reinforcing the meaning of the $I$, hence, conveying the meaning that it is a disturbingly skeletal person (in analogy with the reduplication of adjectives often used in South African English, e.g. skinny-skinny, in which the doubling intensifies the meaning to 'very skinny'.

Example (9) is about three girls who are exposed to the danger of an HIV/AIDS infection daily on their way to school.

$$
\begin{aligned}
& \text { Candace (F, 17): hoe gaan ons maak vir grade } 10 \text { the taxi is difficult Tamang is } \\
& \text { greedy with } \boldsymbol{R} \tilde{\boldsymbol{\imath}} \\
& \text { 'How are we going to do in Grade 10? The taxi is difficult. Ta- } \\
& \text { mang is greedy for blowjobs' } \\
& \text { Carlé (F, 17): } \quad \text { All taxi drivers is full of } \approx+\text { but we need the taxi to go to school } \\
& \text { 'All taxi drivers are full of HIV/AIDS-transmitting behaviour } \\
& \text { but we need the taxi to go to school' } \\
& \text { Kirshny (F, 16): Ja maar R̃̃ \& } \supset \text { is jaki too } \\
& \text { 'Yes but blowjobs with condom are disgusting too' } \\
& \text { Carlé: } \quad \text { I just put education first and } \approx+! \text { second } \\
& \text { 'I just put education first and the risk of an HIV infection second' } \\
& \text { Kirshny: } \quad \text { The Lord shall protect us from } \sim \boldsymbol{+} \text { when } \boldsymbol{R} \tilde{\boldsymbol{I}} \text { Tamang will never } \\
& \text { accept } \supset \\
& \text { 'The Lord shall protect us from an HIV infection when blowjob- } \\
& \text { ing Tamang will never accept a condom' }
\end{aligned}
$$

Candace asks her friends about transportation arrangements to get to school in Grade 10. She doubts whether the (minibus) taxi that Tamang runs from their area of residence to the school is a good option as he is greedy for $R \tilde{\imath}$ 'blowjobs'. The graphic sign $R \tilde{l}$ symbolises a man standing $R$ and another person crouching in front of him depicted by the $i$, who takes in his sperm represented by the tilde above the $\tilde{l}$. Carlé concludes that Tamang is not an exception, but that all taxi drivers show this $\approx+$ 'HIV/AIDS-transmitting behaviour' $(\approx$ or $\sim$ figuratively depicts sperm and, thus, stands for sexual intercourse, as it has been established in previous examples, which is likely to cause an HIV transmission +). Nevertheless, they have no choice than to use the taxis to get to school. Kirshny interjects that $R \tilde{\imath} \& \supset$ 'blowjobs with condoms' are disgusting, too, that is, she presents the option of paying for transportation with a sexual favour as repugnant, no matter whether adequate protection is used or not. Carlé takes a more pragmatic approach to the matter and states that she puts education first, and then resorts to the graphic sign $\approx+$ ! 'risk of an HIV/AIDS infection' (here the ! expresses the risk) to transcend the taboo of actually writing that she consciously risks an infection in order to be able to go to school. Kirshny ends the conversation by trusting in God to not get an HIV/AIDS infection from the blowjobs without a condom. She uses three different graphic signs in this relatively short statement: $\sim+, R \tilde{\imath}, \supset$. This communication exposes the vulnerability of girls and 
women in the Cape Flats in relation to their frequently insufficient financial means. The exchange of sexual favours for material goods and services, such as taxi rides, is common. These, mainly unprotected, sexual favours, contribute greatly to the spread of HIV/AIDS in the Cape Flats.

Facebook users from the Cape Flats often employ graphic signs to narrate how their everyday lives are affected by HIV/AIDS, as examples (7)-(9) illustrate. These three examples reflect the poor living conditions that predominate in the Cape Flats that are characterised by inadequate health care, housing, sanitation, safety, and transportation infrastructure. Such conditions place an undue strain on people suffering from HIV/AIDS because they can lead to a higher infection rate, precipitate the disease, accelerate its course, and cause more fatalities. Due to the severe impact HIV/AIDS has in the Cape Flats, it is not surprising that a lot of stigma is attached to the disease and users prefer to use graphic signs to describe the effects on their everyday practices. However, it is not only the infected people who are afflicted, but also their closer social environment, because, for instance, they share (overcrowded) accommodation, as in (8). Besides, people are suddenly forced to take care of their infected parents, siblings, children, etc. The primary informal caregivers are women in the Cape Flats. In addition, the dire living conditions put the residents at constant risk of an HIV infection. Due to practices as in (9), young women show the highest HIV/AIDS prevalence, several-fold higher than their male peers. Young women tend most to use graphic signs in their Facebook posts.

\subsection{Social functions of the graphic signs}

The importance of the graphic signs goes beyond their direct meaning. It is in most cases not the graphic signs per se which show solidarity and sympathy, labelling and blaming or distancing and othering, but their combination with surrounding words/sentences. Hence, the graphic signs facilitate or enable the above mentioned positioning as they provide an opportunity to transcend the stigma of overtly talking about HIV/AIDS related ailments, challenges and practices.

\subsubsection{Solidarity and sympathy}

Capetonian Facebook users express solidarity and sympathy to people suffering from HIV/AIDS via graphic signs. HIV/AIDS causes great hardship to infected persons and their immediate social environment, as the sections 4.1.1-4.1.3 have shown. Many of the users who dare to speak up about the physical, mental and social effects of HIV/AIDS, the transmission of the disease to them, and their everyday lives with the virus by using graphic signs receive feedback of solidarity and sympathy from other Facebook friends from their social network. In general this uplifting feedback also includes graphic signs.

In example (10), Donovan receives a sympathising response to his complaining about being excluded from society. 
Donovan (M, 34): Die mense is not (I) with me. Hulle is ]]I[[. They dont pick me for work on farms and docks coz I look ;Z!. Not even the Crazy Cats give me jobs

'The people are not socialising with me. They are isolating me. They don't pick me for work on the farms and docks because I look very ill. Not even the Crazy Cats give me jobs'

Lizane (F, 26): $\quad U$ are not alone with $j+j Z$. Come to our prayer group. $U$ will feel ((I)) with us

'You are not alone with HIV/AIDS and its effects. Come to our prayer group. You will feel embraced with us'

Donovan:

I love you. Big hug. Mwah Mwah

Donovan complains that people do not (I) 'socialise' with him and ]]I[[ 'isolate' him. Moreover, he is not picked as a day labourer on the farms or the docks because he apparently looks $i Z$ ! 'seriously ill'. Looking critically ill in South Africa often means that one is associated with HIV/AIDS and, thus, stigmatised. Donovan adds that not even a local gang would hire him to do some small (criminal) jobs for them. Lizane reacts to his grievances by inviting him to her prayer group, where he will feel $((I))$ 'embraced'. She also uses the graphic sign $j+i Z$ in her comment to his post to tell Donovan that he is not alone with HIV/AIDS and its effects. Donovan really appreciates Lizane's reaction.

The graphic signs in example (11) are of two types, the first type are those evolving around being included or excluded from society. The first graphic sign $(I)$ is composed of $I$ representing a person who is not left alone by their fellow human beings ( ). Lizane uses a close variation of this graphic sign $((I))$ in which the effect of feeling included and supported is reinforced through the double brackets. An alteration from this is $]] I[$, in this case the brackets are turned around and in addition they are square brackets instead of round ones. The second type of graphic signs contain the element ; combined with $Z$ (and further elements). The graphic sign $; Z$ ! expresses that Donovan looks very ill. This meaning is made up of the central element $Z$, which depicts the difficult zigzag-path of living with HIV/AIDS, framed by i standing for a disturbing/discomforting experience, and! indicating a risk. Similarly, the graphic sign $j+i Z$ emphasises the discomfort of a life with HIV/AIDS by using $i$ twice. It further stresses that not the effects of any disease are talked about, but those of HIV/AIDS $(+)$.

Moeneeba, in (11), narrates her struggles of enrolling her HIV-positive granddaughter in primary school and Reza encourages her to not give up.

Moeneeba (F, 48):

Joh angry angry! My $\infty+$ baba is not admitted to school. They

say she $+>$... other kiddies

'Joh very angry! My HIV-positive baby is not admitted to school. They say she is transmitting HIV to other kids'

Reza (F, 27): $\quad$ That's absolutely horrible! Don't give up! Jou $\infty+$ baba het niks fout gedoen

'That's absolutely horrible! Don't give up! Your HIV-positive baby hasn't done anything wrong' 
Moeneeba:

Dankie vriendin ek hou baie van jou positiewe worde. Model C schools would take her no matter $+/$ - but the doctors say she must eat well for $>_{-}$and I can't afford both

'Thank you friend I really appreciate your positive words. Model C schools would take her no matter her HIV-status but the doctors say she must eat well to fight the HIV-virus and I can't afford both'

Moeneeba relates that her $\infty+$ 'HIV-positive' granddaughter was not admitted to the primary school of her choice because she could possibly $+>\ldots$. 'transmit HIV' to fellow learners. Reza responds in a sympathetic way stating that it is horrible and encourages her to not give up. She stresses that it is not the child's fault and uses the same graphic signs $\infty+$ as Moeneeba before to express her solidarity. Moeneeba then thanks her for her positive words and further explains that a former Whites-only school would accept the child independently of her HIVstatus, which she expresses through the graphic sign +/-. However, her problem is that the granddaughter requires a healthy, balanced diet to $>_{-}$'fight the HIV-virus', which is costly and does not leave Moeneeba with sufficient funds to pay for the school fees of that particular school. This means that Moeneeba is forced to decide whether to send her grandchild to an expensive school that does not mind the girl's HIV-status or to spend her money on healthy food for her granddaughter. The graphic signs used in example (11) to convey a message of sympathy and solidarity (in combination with words) are, firstly, $\infty+$, in which + refers to a HIV-positive person and $\infty$ specifies that it is a baby (the shape of $\infty$ resembles a bundled up baby). Secondly, the graphic sign $+>\ldots$ is quite straightforward: + stands for HIV-positive, $>\ldots$ represents the spreading of the HIV-virus with the $>$ indicating the direction of spread and the ... depicting the infectious agents. Thirdly, +/- does not require a long explication: + and - simply make reference to a positive respectively negative HIV-status. Lastly, in $>_{-}$the first element represents the virus' potential to spread (inside the body of an infected person and across bodies), and the second element _ depicts the effort to keep the virus down.

Users express their solidarity and sympathy to accounts of the negative impact of HIV/AIDS on people's place in society. At times the stigma of HIV/AIDS can be so overwhelming that even the sympathisers prefer resorting to graphic signs in combination with expressing their support in words. They often have the tendency to use the same or very similar graphic signs as the users to whom they react in order to further align themselves with those. Such statements of solidarity and sympathy are extremely appreciated by the users who have decided to share their difficulties online. More women than men show solidarity and sympathy on Facebook (including graphic signs) to people affected by HIV/AIDS.

\subsubsection{Labelling and blaming}

In contrast to expressing solidarity and sympathy, the graphic signs are also used to label and blame people affected by HIV/AIDS. As the previous examples have demonstrated, users resort to graphic signs to position and label themselves or members of their close social environment as HIV-positive including the different aspects this implies. Therefore, on the one hand, graphic signs make meaningful conversations about HIV/AIDS possible despite the stigma. They facilitate communicating with like-minded people about the physical, mental 
and social effects, the ways of transmission, and their everyday lives with HIV/AIDS. On the other hand, graphic signs sometimes also enable users to negatively label and blame people affected by HIV/AIDS, to insult them and reinforce their stigmatisation.

Example (12) showcases an instance of two interlocutors using graphic signs to negatively label and blame each other.

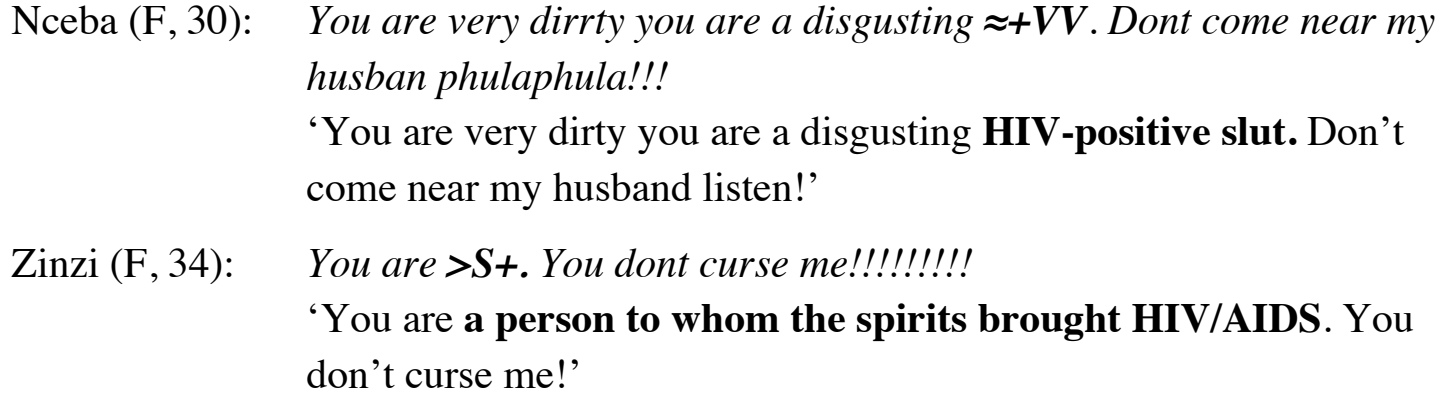

Nceba calls Zinzi dirty, labels her a $\approx+V V$ 'HIV-positive prostitute', and consequently cautions her not to approach her husband. In return, Zinzi positions Nceba with the help of the graphic sign $>S+$ as a 'person to whom the spirits brought HIV/AIDS'. This is not only a positioning of the other as HIV-positive, which in the context of the stigmatisation of the disease in the Cape Flats equals an insult. Zinzi's insulting action is even stronger because she does not simply position Nceba as an HIV-infected person, but as somebody who misbehaved/"sinned" and, hence, the spirits inflicted HIV/AIDS on her as a punishment. Cape Flats residents tend to perceive this as a more extreme positioning as Nceba labelling her as an HIV-positive prostitute (as the witchcraft element is more stigmatised than prostitution).

The two graphic signs in example (12) are used to (negatively) label and blame others. The graphic sign $\approx+V V$ consists of three elements, of which the first two have already appeared in previous examples. In short, $\approx$ stands for heterosexual intercourse (sperms) and + for HIVpositive, that is, so far, HIV is transmitted from a man to a woman. The third element $V$ figuratively depicts a woman who (willingly) spreads her legs to have sexual intercourse. As the element is reduplicated it indicates that this happens frequently, thus, the meaning of prostitute. The second graphic sign $>S+$ is a combination of three elements, too, all of which have already been discussed earlier. Here they are merged to express that the spirits brought HIV/AIDS to Nceba: > stands for the way of transmission, $S$ for the spirits, and + for HIV.

In example (13), Aryn resorts to graphic signs to forcibly disclose the HIV-positive status of Shamielah.

(13) Aryn (M, 22):

Hy everybody. Shamielah has had and now she is $\sim+! ! !$ SHAMIELAH IS A + V!!!

'Hy everybody. Shamielah has had a lot of sexual intercourse and now she is HIV-positive! Shamielah is a HIV-positive slut!'

Kenwyn (M, 24): Aryn, forced disclosure is not nice

Aryn starts his post with Hy everybody, thus, addresses it to a broad audience. He claims that Shamielah has had 'much sexual intercourse' and as a consequence is $\sim+$ 'HIV-positive'. Furthermore, he concludes that Shamielah is a $\sim+V$ 'HIV-positive slut'. Aryn, thus, uses three graphic signs to label her as HIV-positive and blames her for this sta- 
tus. Kenwyn condemns the way (on Facebook) Aryn forcibly discloses Shamielah's HIVstatus. In example (13) the graphic signs depict the following: $\sim \sim \sim \sim \sim \sim \sim \sim \sim \sim \sim \sim \sim \sim \sim$ is a repetition of the element $\sim$, which represents sperm and hence stands for sexual intercourse, or in this case a lot of sexual intercourse. Next, $\sim+$ means an HIV-transmission through sexual intercourse. The last $\sim+V$ is a variation of the graphic sign $\approx+V V$ in example (12).

Graphic signs are used to label and blame (the other) in terms of HIV/AIDS. For users, who have the courage to communicate about their experiences with HIV/AIDS in a climate of taboo and stigma, the graphic signs work as means to position themselves and others affected in meaningful ways. Nevertheless, some users abusively label and blame others through graphic signs. There are more cases of women being labelled negatively and blamed, and especially they are exposed to more insulting instances of negative positioning and labelling as in examples (12) and (13). This offensive use of graphic signs towards women often presents them as wrongdoers, as those to bear the blame themselves for the HIV-infection.

\subsubsection{Distancing and othering}

The negative labelling and blaming of others through graphic signs often leads to distancing from HIV-infected persons and othering them. This is similar to the labelling and blaming in the previous section; however, while in section 4.2.2 the interlocutor or a third party is attributed a negative label and blamed for their HIV-status by their actions, in this section an (implicit) comparison between the immaculate/well-behaved user and an unrighteous/misbehaved third party happens. Some users construct the other in their Facebook posts/small stories as radically different from themselves in order to position the other as HIV-positive (and themselves as HIV-negative) through graphic signs. Moreover, they use strategies of othering by denying them a clearly defined status and just designating them as "anomalous", "peculiar", or "deviant". In addition, they create a distance between themselves and the HIV-positive other. This means that being HIV-positive - being the distant other - is further stigmatised in the posts of these users.

Nusradee, in example (14), others the subject of her conversation as socially different and, thus, HIV-positive.

(14) Nusradee (F, 27):

I have nothing to do with her. She is Black, she goes to HAppy Clappy Church. She is for sure ${ }^{+}+$. Ek is Kalid, Slams and definitief gesond

'I have nothing to do with her. She is Black, she goes to Zionist Church. She is for sure suffering from HIV/AIDS. I am Coloured, Muslim and definitely healthy'

Sigmonne (F, 36): Did you go $\boldsymbol{H}$ ? ?

'Did you go testing?'

Nusradee:

No. I just know. I can feel it

Nusradee writes in the beginning of her initial post that she has nothing to do with her - the distant other. Nusradee goes on to describe that she [the woman pictured in Nusradee's post] is Black and attending Zionist Church. Based on these differences she concludes that the subject of her conversation is certainly i+ 'suffering from HIV/AIDS'. This graphic sign is a 
composition of + 'HIV-positive' preceded by $i$, which here means being in discomfort, or in other words, suffering. She constructs herself as different from the person she is talking about in terms of race and religion, and in her logic, consequently, also of their HIV-status. This opposition is reinforced by the code-switch from English to Afrikaans. Thus, she creates a distance between her and the other, in order to legitimise her claims that the other is HIVpositive. In the end, it turns out that when Sigmonne asks her if she went H? 'HIV-testing', she did not. Nusradee asserts to simply know, to feel that she is HIV-negative, which in her logic, in which only the deviant other can possibly have an HIV-infection, makes sense. The graphic sign used to ask if Nusradee went testing $H$ ? can be explained in different ways, especially the first element: $H$ is either a figurative depiction of a common layout of health clinics in the Cape Flats, where local people would go for HIV-testing. In other words, the architectural structure with regards to the groundplan of the health clinics resembles the form of an $H$. Or alternatively, $H$ is short for 'hospital'. The second element is clearer, ? stands for an enquiry/a test.

Example (15) is an account of a prison gang member who uses HIV/AIDS-related graphic signs to position his former prison wife ${ }^{7}$ as other and distant.

Brontthews (M, 45): I am general of the 28 and I have 31 murder cases behind my name and I am very loyal to Nongoloza's rules and I have always kept myself clean and healthy as my mama tautght me. Daai $\approx+$ masepoes who served as my wifie is a very shady person he has no morals and backbone just a few inkings he is a complete sellout and he give me $j^{+}$. When I get that $<<+$ dirty basterd in my hands I cut his face

'I am general of the $28 \mathrm{~s}$ and I have 31 murder cases behind my name and I am very loyal to Nongoloza's rules and I have always kept myself clean and healthy as my mummy has taught me. That HIV-positive son of a bitch who served as my prison wife is a very shady person he has no morals and backbone just a few tattoos he is a complete sell-out and he has given me HIV/AIDS. When I get that HIV-spreading dirty bastard in my hand I cut his face'

Brontthews first presents himself as an honourable, loyal senior gang member of the 28 prison gang. In addition, he affirms to always have kept himself clean and healthy. In the second part of his post, he constructs his former prison wife as an immoral and unfaithful nobody. Moreover, Brontthews uses three different graphic signs to label him as HIV-positive or HIVspreading: $\approx+, j+$, and $<<+$. Hence, he blames his former sexual partner of having transmitted HIV to him. He threatens to cut the other's face as a punishment which would take away his identity, especially as he might have tattoos on his face. In other words, Brontthews distances himself from the other and positions the other as deviant in order to other him as HIVpositive and even blame that other for transmitting the disease to him. The graphic first sign

\footnotetext{
7 A "weaker" inmate who befriends a "more powerful" fellow prisoner, mainly for protection. In exchange the "wife" is expected to do domestic work, such as tidying up the cell or making tea. In addition, they are expected to be available for sex to their "husbands".
} 
in example $(15) \approx+$ is used here to mean 'HIV-positive', including the information that the virus was transmitted through sexual intercourse $\approx$. The next graphic sign $i+$ refers to HIV/AIDS, but also mentions the discomfort ; HIV/AIDS entails. Finally, $<<+$, apart from the element + depicting HIV(-positive), contains the element $<$, which represents the spread of HIV. The repetition of $<$ implies that this person spreads HIV widely.

Some users employ HIV/AIDS-related graphic signs as acts of distancing and othering. This contributes greatly to the stigmatisation of HIV/AIDS, as it is associated with people different from oneself, and constructed as something distant from oneself. The distance created between themselves and the others allows those users to position themselves as unrelated to HIV/AIDS, to condemn the otherness of HIV-positive persons and blame them for spreading the virus.

\section{$5 \quad$ Discussion}

This paper explored how South African users resort to graphic signs in HIV/AIDS discourse online. It also approached the question to what extent the use of graphic signs is a gendered practice. Results show that users from the Cape Flats employ HIV/AIDS-related graphic signs to cover three (interrelated) main topics, which otherwise probably would not be addressed to the same extent due to the stigmatisation of HIV/AIDS and all kinds of related issues. The first topic is the physical, mental and social effects of HIV/AIDS, which covers a wide array of symptoms ranging from itchiness over anxiety to social isolation. The second topic is the way of transmission of HIV/AIDS. In the case of the study participants it is either a transmission from mother to infant or through sexual intercourse. The latter involves experiences of sexual violence for many women. The third topic is everyday life with HIV/AIDS, which is strongly determined by the deplorable living conditions in large parts of the Cape Flats. Two aspects particularly affect the everyday life of women: they are often the caregivers of HIVinfected relatives and young women have a much higher infection rate than their male peers. Furthermore, users from the Cape Flats employ HIV/AIDS-related graphic signs to construct social relationships through positioning. They use graphic signs to express solidarity and sympathy with people affected by HIV/AIDS, to (negatively) label and blame the other, to create a sense of otherness and distance. Thus, in the South African context, Facebook/social media have become an important space and means for communicating HIV/AIDS issues.

The graphic signs in general consist of two or three elements. These elements are arranged in two different patterns: either they are read from left to right or there is a central element framed on both sides by the same element. The elements constituting the graphic signs can be combined in manifold ways, which in addition to the slight variation in similar elements and meanings, leads to an infinite set of potential graphic signs. The graphic signs, respectively the constituting elements, are in many cases graphic (both in the sense of pictorial and of a vivid description) depictions of shapes and actions. Moreover, in some cases the first letter of a specific term is an element in a graphic sign. In other cases, such as in + the character's meaning stands for a particular HIV/AIDS-related meaning. The graphic signs can only be understood in the specific social setting of the Cape Flats since they present the conventions invented to reflect the reality imagined and constructed by the local sign-makers, a reality in which graphic signs are used to circumvent the taboo of talking about HIV/AIDS. However, 
graphic signs are not used to prevent outsiders from knowing that the topic of conversation in the Facebook posts is HIV/AIDS. They are used to avoid the overt naming of the disease and related issues. This is to comply with the "social norms" of the HIV/AIDS stigma in South Africa. Not following these "norms" could mean that speakers are discriminated against or that - in their beliefs - they would suddenly suffer from HIV/AIDS as a punishment from the spirits/witchcraft.

Graphic signs are creative and artful. They are fleeting, momentary, non-routine, short displays of linguistic skills embedded in everyday social practices. They are a means of creating, negotiating, and displaying social meaning. Hence, they are small performances or acts of stance-taking. The users from the Cape Flats use these small performances to challenge the stigma and silence of HIV/AIDS - to say the unsayable through graphic signs. Their small performances subvert the dominant narrative of issues that are taboo and cannot be named or spoken. Small performances/stories perform important functions and actions in people's everyday lives. The Cape Flats users also resort to small performances/stories to create a sense of who they are both in the interactional moment as well as in relation to the dominant discourses which constitute their context (Bamberg/Georgakopoulou 2008: 379). This "sense of who they are" is co-constructed by the interlocutors - it is a discursive production of the self and other or positioning. Positioning is an interactional phenomenon producing interpersonal relations and results in a relational and performative view of self and other (Davies/Harré 1990: 47). The users from the Cape Flats use graphic signs to perform small stories about their experiences with HIV/AIDS. In their Facebook interactions users position the self and the other in the sphere of HIV/AIDS stigma and silence by means of these graphic signs. The sum of these small performances containing HIV/AIDS-related graphic signs gives us insight into the "big story" of HIV/AIDS in the Cape Flats and its stigmatisation and silencing.

As this is the first study on HIV/AIDS- related graphic signs in online small performances, evidently, more research is needed. The topic requires to be analysed within a pragmatic framework to better understand the power and identity relations in the short interactions between users. It also needs to be examined how the use of graphic signs is embedded in other everyday digital practices in the Cape Flats and if they are just as widespread on other social media platforms as on Facebook. However, the most pressing need is, without any doubt, more research and actions on how the spread of HIV/AIDS and the attached stigma can be stopped. The findings of this study could be applied to tailor an accessible HIV/AIDS prevention campaign based on graphic signs to target those residents of the Cape Flats that are not fully reached with more conventional campaigns. Including the graphic signs in HIV/AIDS prevention would allow to specifically target those most at risk, namely, young women, who appear to be the most prone to use such graphic signs on Facebook. ${ }^{8}$ The graphic signs might also hold the potential for local users, particularly women, to peer-educate and support each other on HIV/AIDS-related issues. In other words, the conscious use of graphic signs could result in grassroot HIV/AIDS awareness-raising and prevention.

\footnotetext{
${ }^{8}$ Women are responsible for the use of $73 \%$ of the graphic signs, young women have employed $41 \%$ of all graphic signs analysed.
} 


\section{References}

Anthonissen, Christine/Meyer, Bernd (2008): "Question-answer sequences between doctors and patients in a South African HIV/AIDS day clinic". Stellenbosch Papers in Linguistics 36: 1-34. doi: 10.5842/36-0-37.

Ashforth, Adam (2001): AIDS, witchcraft, and the problem of power in post-apartheid South Africa. Unpublished research paper.

Bamberg, Michael/Georgakopoulou, Alexandra (2008): "Small stories as a new perspective in narrative and identity analysis". Text \& Talk 28/3: 377-396. doi: 10.1515/TEXT.2008.018.

Bauman, Richard (1977): Verbal Art as Performance. Rowley/MA: Newbury.

Bauman, Richard (2000): "Language, identity, performance". Pragmatics 10/1: 1-5. doi: 10.1075/prag.10.1.01bau.

Bauman, Richard (2011): "Commentary: Foundations in performance". Journal of Sociolinguistics 15/5: 707-720. doi: 10.1111/j.1467-9841.2011.00510.x.

Black, Steven P. (2013): "Stigma and ideological constructions of the foreign: Facing HIV/AIDS in South Africa". Language in Society 42: 481-502. doi: 10.1017/S004740 4513000638.

Bond, Virginia/Chase, Elaine/Aggleton, Peter (2002): "Stigma, HIV/AIDS and prevention of mother-to-child transmission in Zambia". Evaluation and Program Planning 25/4: 347356. doi: 10.1016/S0149-7189(02)00046-0.

Campbell, Catherine/Nair, Yugi/Maimane, Sbongile/Nicholson, Jillian (2007): “'Dying twice': A multi-level model of the roots of AIDS stigma in two South African communities". Journal of Health Psychology 12/3: 403-416. doi: 10.1177/1359105307076229.

Davies, Bronwyn/Harré, Rom (1990): "Positioning: The discursive production of selves". Journal for the Theory of Social Behaviour 20: 43-63. doi: 10.1111/j.1468-5914.19 90.tb00174.x.

De Fina, Anna (2008): "Who tells which stories and why? Micro and macro contexts in narrative". Text \& Talk 28/3: 421-442. doi: 10.1515/TEXT.2008.020.

De Fina, Anna/Schiffrin, Deborah/Bamberg, Michael (eds.) (2006): Discourse and Identity. Cambridge: Cambridge University Press.

Delius, Peter/Glaser, Clive (2005): "Sex, disease and stigma in South Africa: Historical perspectives". African Journal of AIDS Research 4/1: 29-36. doi: 10.2989/16085900 509490339.

Deumert, Ana (2014): Sociolinguistics and Mobile Communication. Edinburgh: Edinburgh University Press.

Deumert, Ana (forthcoming): “Tsotsitaal online - The creativity of tradition”. In: Cutler, Cecelia/Røyneland, Unn (eds.): Analyzing Multilingual Youth Practices in Computer Mediated Communication. Cambridge: Cambridge University Press.

Duffy, Lynne (2005): "Suffering, shame, and silence: The stigma of HIV/AIDS". Journal of the Association of Nurses in AIDS Care 16/1: 13-20. doi: 10.1016/j.jana.2004.11.002.

Farmer, Paul (2003): Pathologies of Power: Health, Human Rights, and the New War on the Poor. Los Angeles: University of California Press.

Foucault, Michel (1978): A History of Sexuality. Vol. 1. New York: Pantheon.

Georgakopoulou, Alexandra (2007): Small Stories, Interaction, and Identities. Amsterdam: Benjamins. 
Goffman, Erving (1963): Stigma: Notes on the Management of Spoiled Identity. New York: Simon \& Schuster.

Herek, Gregory M. (2002): "Thinking about AIDS and stigma: A psychologist's perspective". Journal of Law, Medicine and Ethics 30: 594-607. doi: 10.1111/j.1748-720X.2002.tb 00428.x.

Herek, Gregory M./Capitanio, John P./Widaman, Keith (2003): "Stigma, social risk, and health policy: Public attitudes toward HIV surveillance policies and the social construction of illness". Health Psychology 22/5: 533-540. doi: 10.1037/0278-6133.22.5.533.

Jaffe, Alexandra (ed.) (2009): Stance. Sociolinguistic Perspectives. Oxford: Oxford University Press.

Kress, Gunther/van Leeuwen, Theo (1996): Reading Images. The Grammar of Visual Design. London: Routledge.

Liamputtong, Pranee (ed.) (2013): Stigma, Discrimination and Living with HIV/AIDS. A Cross-Cultural Perspective. Dordrecht: Springer.

Masquillier, Caroline/Wouters, Edwin/Mortelmans, Dimitri/le Roux Booysen, Frederik (2015): "The impact of community support initiatives on the stigma experienced by people living with HIV/AIDS in South Africa". AIDS Behavior 19/2: 214-226. doi: 10.1007/s10461-014-0865-1.

Maughan-Brown, Brendan (2010). "Stigma rises despite antiretroviral roll out. A longitudinal analysis in South Africa". Social Science \& Medicine 70: 368-374. doi: 10.1016/j.socsci med.2009.09.041.

Morrell, Robert (2003): "Silence, sexuality and HIV/AIDS in South African schools". The Australian Educational Researcher 30/1: 41-62. doi: 10.1007/BF03216780.

Ogden, Jane/Nyblade, Laura (2005): Common at its Core: HIV and AIDS Stigma across Contexts. Washington/DC: ICRW.

Oostendorp, Marcelyn/Bylund, Emanuel (2012): "Emotions and HIV/AIDS in South Africa: A multilingual perspective”. Stellenbosch Papers in Linguistics 41: 77-89. doi: 10.5842/ 41-0-84.

Parker, Richard/Aggleton, Peter (2003): "HIV and AIDS-related stigma and discrimination: A conceptual framework and implications for action”. Social Science \& Medicine 57/1: 13 24. doi: 10.1016/S0277-9536(02)00304-0.

Saal, Elvis (2012): "To use or not to use teenage Afrikaans in HIV prevention messages directed at Afrikaans teenagers in Pretoria”. Stellenbosch Papers in Linguistics 41: 91-105. doi: $10.5842 / 41-0-85$.

Selikow, Terry-Ann (2004): “'We have our own special language'. Language, sexuality and HIV/AIDS: A case study of youth in an urban township in South Africa". African Health Sciences 4/2: 102-108.

Shisana, Olive/Simbayi, Leickness C. (2002): Nelson Mandela/HSRC Study of HIVIAIDS: South African National HIV Prevalence, Behavioral Risks and Mass Media, Household Survey 2002. Cape Town: Human Sciences Research Council.

Shisana, Olive/Rehle, Thomas/Simbayi, Leickness C./Zuma, Khangelani/Jooste, Sean/Zungu, Mpumi/Labadarios, Demetre/Onoya, Dorina (2014): South African National HIV Prevalence, Incidence and Behaviour Survey, 2012. Cape Town: Human Sciences Research Council. 
Stadler, Jonathan (2003): "Rumor, gossip and blame: Implications for HIV/AIDS prevention in the South African lowveld". AIDS Education \& Prevention 15/4: 357-368. doi: 10.1521/aeap.15.5.357.23823.

Steward, Wayne T./Herek, Gregory M./Ramakrishna, Jayashree/Bharat, Shalini/Chandy, Sara/Wrubel, Judith/Ekstrand, Maria L. (2008): "HIV-related stigma: Adapting a theoretical framework for use in India”. Social Science \& Medicine 67/8: 1225-1235. doi: 10.1016/j.socscimed.2008.05.032.

Thomas, Felicity (2006): "Stigma, fatigue and social breakdown: Exploring the impacts of HIV/AIDS on patient and carer well-being in the Caprivi Region, Namibia". Social Science \& Medicine 63/12: 3174-3187. doi: 10.1016/j.socscimed 2006.08.016.

UNAIDS: www.unaids.org/en/regionscountries/countries/southafrica [27.12.2016].

Van Damme, Wim/Kober, Katharina/Kegels, Guy (2008): "Scaling-up antiretroviral treatment in Southern African countries with human resource shortage: How will health systems adapt?". Social Science \& Medicine 66/10: 2108-2121. doi: 10.1016/j.socsci med.2008.01.043.

Volks, Cal (2004): "The role of tertiary institutions in the HIV/AIDS epidemic". In: Kauffman, Kyle D./Lindauer, David L. (eds.): AIDS and South Africa: The Social Expression of a Pandemic. New York, Palgrave Macillan: 161-175.

\section{Bionote}

Nadine Chariatte is a Postdoctoral Research Fellow at the University of Cape Town, focusing on linguistic practices in post-apartheid South Africa. She holds a $\mathrm{PhD}$ in Sociolinguistics from the University of Bern. Nadine Chariatte has conducted research on the sociolinguistics of the Cape Flats (Cape Town), the variety of Spanish spoken in Malaga, and digital discourse across a range of social media platforms. Her research interests include sociolinguistics, computer-mediated communication, discourse analysis, language and identity, language and space. 